\title{
Wohnen im Alter
}

\author{
Heterogene Gesellschaft bedarf kreativer Lösungen
}

Die zunehmend älter werdende Gesellschaft und veränderte Formen des $\mathrm{Zu}$ sammen- oder eben nicht Zusammenlebens stellen die Gesundheitsversorgung bereits heute vor eine große Herausforderung. In Zukunft werden diese Herausforderungen noch größer werden und erfordern strukturell-kreative Lösungen.

Dem Bereich Wohnen im Alter wird dabei ein großer Stellenwert zukommen. Die wenigsten Menschen möchten ihren Lebensabend in der Lebensform Pflegeheim verbringen - als alter Mensch unter vielen alten Menschen. Mobilität und wechselnde Familienbeziehungen führen aber dazu, dass immer mehr Menschen im Alter alleine leben. Werden sie pflegebedürftig, ist es schwierig, sie weiterhin daheim zu versorgen.
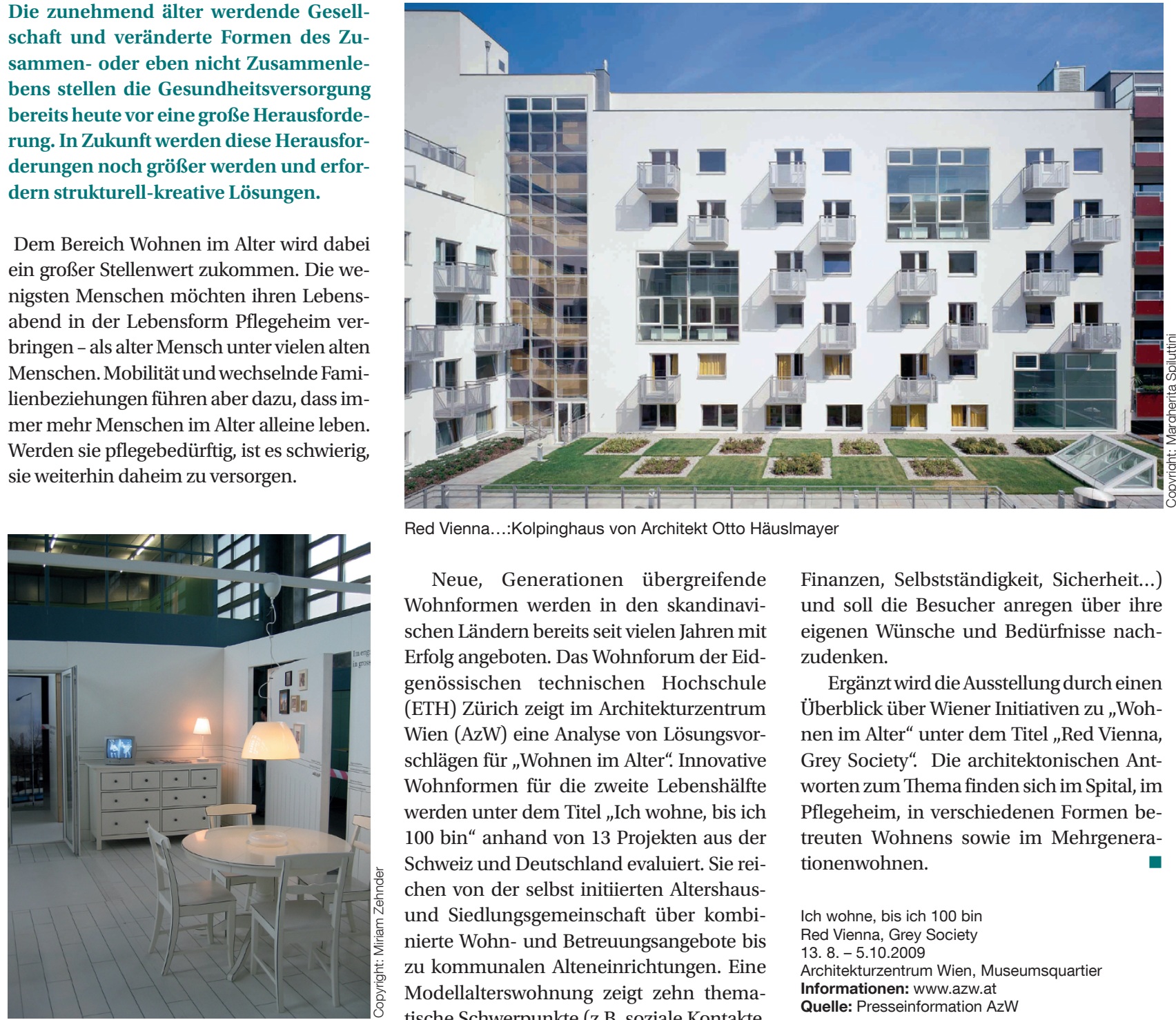

Red Vienna...:Kolpinghaus von Architekt Otto HäusImayer

Neue, Generationen übergreifende Wohnformen werden in den skandinavischen Ländern bereits seit vielen Jahren mit Erfolg angeboten. Das Wohnforum der Eidgenössischen technischen Hochschule (ETH) Zürich zeigt im Architekturzentrum Wien (AzW) eine Analyse von Lösungsvorschlägen für „Wohnen im Alter“. Innovative Wohnformen für die zweite Lebenshälfte werden unter dem Titel „Ich wohne, bis ich 100 bin" anhand von 13 Projekten aus der Schweiz und Deutschland evaluiert. Sie reichen von der selbst initiierten Altershausund Siedlungsgemeinschaft über kombinierte Wohn- und Betreuungsangebote bis zu kommunalen Alteneinrichtungen. Eine Modellalterswohnung zeigt zehn thematische Schwerpunkte (z.B. soziale Kontakte,
Finanzen, Selbstständigkeit, Sicherheit...) und soll die Besucher anregen über ihre eigenen Wünsche und Bedürfnisse nachzudenken.

Ergänzt wird die Ausstellung durch einen Überblick über Wiener Initiativen zu „Wohnen im Alter“ unter dem Titel „Red Vienna, Grey Society“. Die architektonischen Antworten zum Thema finden sich im Spital, im Pflegeheim, in verschiedenen Formen betreuten Wohnens sowie im Mehrgenerationenwohnen.

Ich wohne, bis ich 100 bin

Red Vienna, Grey Society

13. 8. - 5.10.2009

Architekturzentrum Wien, Museumsquartie

Informationen: www.azw.at

Quelle: Presseinformation AzW

Die eigenen Wünsche und Bedürfnisse erforschen.

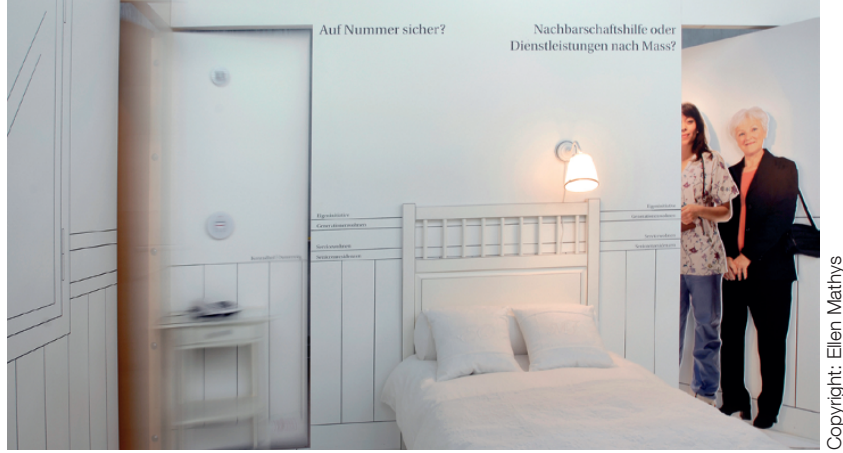

Ich wohne, bis ich 100 bin

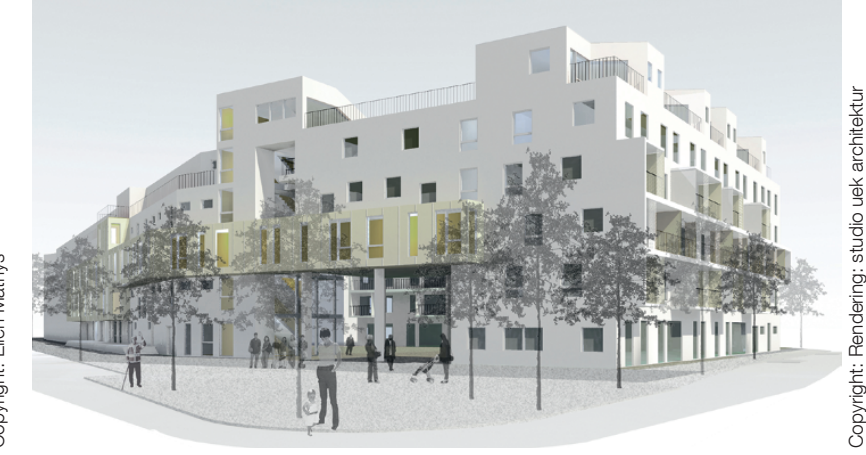

Grey Society: Projekt Oase 22 von studio uek architektur 